Article

\title{
Food Swamps and Poor Dietary Diversity: Longwave Development Implications in Southern African Cities
}

\author{
Bruce Frayne *(1) and Cameron McCordic * \\ School of Environment, Enterprise and Development (SEED), Faculty of Environment, University of Waterloo, \\ 200 University Avenue West, Waterloo, ON N2L 3G1, Canada \\ * Correspondence: bfrayne@uwaterloo.ca (B.F.); c2mccordic@uwaterloo.ca (C.M.)
}

Received: 1 November 2018; Accepted: 24 November 2018; Published: 27 November 2018

check for updates

\begin{abstract}
While the literature on food deserts focuses on limited availability of food in urban settings, 'food swamps' may better characterize the extensive prevalence and accessibility of cheap, highly processed foods. For urban populations, access to nutritionally inadequate poor-quality food has dire developmental consequences. The long-wave impacts of malnutrition at gestational and early childhood stages are negative and can be non-reversible. Moreover, those who survive into adulthood may face a lifetime of sub-optimal physical and mental development that undermines the second and third UN Sustainable Development Goals— to end hunger and to ensure healthy lives. This paper assesses the long-term health vulnerability of children with limited access to adequate and nutritious food in rapidly urbanizing cities. The analysis focuses on the African Urban Food Security Network (AFSUN) data drawn from 6453 household surveys in 11 cities and nine countries in Southern Africa. The results indicate that children in these households are consuming a limited diversity of food, have limited access to resources and have greater odds of experiencing both short-term and long-term food and nutrition insecurity. These findings demonstrate an underlying vulnerability to long-term health impacts stemming from nutritionally inadequate diets, with potentially significant costs to human capital.
\end{abstract}

Keywords: food deserts; food security; malnutrition; children; urbanization; Southern Africa

\section{Introduction}

The United Nations' 2030 Agenda poses two direct development challenges that pivot on Sustainable Development Goal (SDG) 11: Sustainable Cities. These challenges are captured under SDG 2: Zero Hunger, and SDG 3: Good Health and Well-Being. Cities of the Global South have become a "ground zero" for these compounding challenges. This investigation assesses the poverty, food security and food consumption characteristics of poor urban households in Southern Africa containing children aged 5 years old and younger. The findings identify household vulnerabilities to longwave nutrition-related health hazards faced by the children growing up in these environments.

The urban transition unfolding across the Global South has the potential to create great prosperity and provide the means by which these SDGs can be achieved. Cities provide economies of scale that make global sustainability possible [1]. However, accessible, nutritious food is a key component without which hunger cannot be eliminated, nor can good health and well-being be achieved [2]. Yet the promise of ending hunger and achieving good health for all is a major challenge in the context of the rapid urbanization of the Global South $[3,4]$. Sprawling informal settlements are now a common feature of the urban form alongside the rise of megacities (cities with more than one million residents) in the developing world [5-13]. Typically associated with rural populations, hunger and malnutrition are now increasingly associated with urban populations [2,14-16]. As a result, "malnutrition is in turn 
a major contributor to both mortality and morbidity and is consequently also a vexing development problem, the locus of which is increasingly urban" [16] (p. 119).

Notwithstanding the positive development potential of widespread urbanization in Sub-Saharan Africa, the continent remains beset by persistent hunger and malnutrition [14-17]. Research indicates that the long-wave demographic impacts of malnutrition at gestational and early childhood stages are negative and non-reversible [18-20]. Moreover, those who survive into adulthood many face a lifetime of sub-optimal physical and mental development that undermines the second and third UN Sustainable Development Goals - to end hunger and to ensure healthy lives [18,21-24].

Hunger and malnutrition are part of the epidemiological transition that is also underway in the Global South. The epidemiological transition describes a shift in the determinants of morbidity and mortality from predominantly communicable diseases (e.g., tuberculosis, influenza, hepatitis) towards predominantly non-communicable diseases (e.g., heart disease, cancer, diabetes) [25]. While the epidemiological transition has been a helpful conceptualization of changing disease prevalence, the theory has evolved as empirical evidence has come to light. As an example, Harper and Armelagos [26] note that new infectious diseases have begun to emerge and spread because of antimicrobial resistance and globalization. The theory has also expanded to include socio-economic factors that have been identified as drivers of the epidemiological transition [27]. Wilkinson [28] highlighted the role of socio-economic inequality in mortality trends linked to the epidemiological transition. In response, Santosa et al. [29] recommended further research into the socio-economic determinants of health to inform needed revisions in the evolving concept. Dye et al. [30] identified a specific interaction between the prevalence of tuberculosis infection rates, and diabetes in a study of India and South Korea. This study noted the role of urbanization (the urban transition) as well as nutrition as key drivers of the epidemiological transition in these countries. Uauy and Kain [31] highlighted the growing need to focus on obesity prevention, in addition to malnutrition, in nutrient programming. This point was reiterated by Broyle et al. [32] who identified a growing pandemic of childhood obesity, driven in part by socio-economic factors like household income.

As would be expected under these transitions, global human nutrition itself is in a state of flux and is described by a third shift: the nutrition transition. As outlined by Drewnowski and Popkin [33], the nutrition transition refers to the shift from the consumption of carbohydrates and fibers to sugars and saturated fats. This transition has been linked to the epidemiological transition through the health outcomes of this dietary shift. Shetty [34] notes the growing challenge of obesity and non-communicable diseases resulting from the nutrition transition. Popkin $[35,36]$ noted that the speed of the nutrition transition appears to differ between the Global North and South. This observation has been conceptualized as the "dual burden" of nutrition where developing countries are faced with a high prevalence of diseases stemming from both under-weight and over-weight populations [37]. In other words, rather than proceeding through the nutrition transition, many developing countries are faced with the burden of both widespread hunger and obesity (or a dual burden). The urban poor are particularly at risk in these countries, where food systems have evolved to accommodate cheap processed food high in sugar and saturated fat [38]. Popkin [39] notes that the nutrition transition in the developing world may also be linked to the urban transition, with urban diets and activity levels becoming increasingly distinct from rural diets and activity levels [40].

Together, these transitions highlight a shift in the vulnerability profile of poorer communities that mirrors the transition from rural to urban livelihoods. These transitions indicate a growing public health threat to future urban residents in the Global South. Children growing up in an environment of limited access to nutritious food are at an increased risk of developing chronic diseases into adulthood [41]. The co-occurrence of stunting and obesity among poor urban neighborhoods is indicative of a food system where highly processed food are more easily accessed while nutritional food is often out of reach to poor families [42]. This situation is highlighted particularly in the context of Southern African cities [43-45]. 
The rapid growth of these cities has also strained the food systems supporting the urban populations in the Global South, leaving pockets of food deserts in many Southern African cities. In a study of Cape Town, Battersby, and Peyton [46] note that the geographic distribution of supermarkets across the city limits access for poor households. Those supermarkets that are in poor areas of the city often stock fewer healthy foods than are available among supermarkets in high-income areas. This practice may be interpreted as a form of retail redlining, where food retailers, often driven by profit margins, are unwilling to service certain vulnerable sectors of the population or provide inferior goods and services in those areas [47]. In response to this limited accessibility, poor households in the city often rely on informal food markets [48]. As a result, the urban food desert has been criticized as having too narrow a view of the urban food system in the Global South [49]. While traditionally defined by limited geographic availability of supermarkets [50], Crush and Battersby [51] note that the concept of food deserts in the African context often ignores the informal economy and the importance of food access rather than availability. Battersby [52] further highlights the importance of accounting for non-market food sources. This investigation posits that given that supermarkets are not the only indicator of the presence or absence of food availability, the idea of a food desert might be more usefully thought of as a food swamp-readily available, cheap, poor quality and nutritionally inadequate food $[53,54]$. The existence of this kind of food swamp (both in terms of food source availability and nutritional diversity) poses a significant threat to the long-term health of poor urban households in Southern Africa [43].

The health impacts of this food system on poor urban households are keenly felt among children. Popkin [35] notes that the regular intake of sugars and saturated fats during early childhood could have significant implications for the prevalence of non-communicable diseases later in life. Caesar et al. [55] further suggest that the food insecurity may be linked to communicable diseases (like HIV and TB) in Southern African cities through circuitous socio-economic poverty. Crush et al. [56] suggest that food insecurity and HIV may share a cyclical relationship via precarious and uncertain household income. Household members carrying these diseases often require greater nutritional diversity but are unable to afford it, further progressing the disease impacts.

It is within this broad developmental context that this paper assesses the odds of exposure to health risks for children, precipitated by limited access to adequate and nutritious food in rapidly urbanizing cities. This investigation has two research objectives: First, to determine the change in the odds of household food insecurity among poor urban households in Southern Africa based on whether those households contain children aged 5 years old and younger. This objective assesses the distribution of food insecurity to assess the positioning of these households in access-defined food deserts/swamps. Second, to describe the food security and poverty characteristics of poor urban households with children 5 years old and younger in Southern Africa. This objective identifies the vulnerability of these households according to their nutrition access and adaptive capacity. The analysis focuses on the African Urban Food Security Network (AFSUN) data drawn from household surveys in 11 cities and nine countries in Southern Africa. This investigation argues that nutrition-related health outcomes are less a consequence of food deserts as they are of highly constrained access to already available food in these cities by individuals and households, and that cheap, processed, and nutritionally poor foods dominate food affordability. This investigation provides novel insight into the experiences of urban food swamps among households with small children in Southern Africa by going beyond the spatial availability of food and directly assessing the food access patterns of these households to determine their nutrition-related vulnerabilities.

\section{Materials and Methods}

\subsection{Approach and Limitations}

To achieve this study's research objectives, this investigation relied on household survey data and nonparametric statistics. Household surveys are a common method for understanding the food 
consumption patterns of a large population where direct observation is often logistically unfeasible. That said, urban household surveys, particularly among poor households, are challenging given the rapidly changing nature of cities in the Global South. In response to this challenge, this study's household survey was completed in partnership with local institutions and experts in each sampled city to ensure that the survey design and sampling was guided by the most up-to-date research, census data and maps. The use of nonparametric statistics in this investigation allowed for direct comparison of groups of household respondents categorized by variables of interest (e.g., food security, food consumption, household demographics). While neither open to causal interpretation or precise predictive modeling, these methods provide accurate and interpretable descriptions of the health vulnerabilities of poor households housing young children.

\subsection{Research Objectives}

Determine the change in the odds of household food insecurity among poor urban households in Southern Africa based on whether those households contain children aged 5 years old and younger.

Describe the food security and poverty characteristics of poor urban households with children 5 years old and younger in Southern Africa.

\subsection{Sample}

The sample for this investigation was drawn from a survey of 6453 poor households sampled using systematic and random sampling across 11 cities in 9 countries in Southern Africa. From that original survey sample, this investigation selected only those households containing children 5 years old and younger. This revised sample contained 2499 poor households distributed across the sampled cities. Both samples are demonstrated in Table 1.

Table 1. The Household Sample Distributed Across the Sampled Cities.

\begin{tabular}{ccccc}
\hline & \multicolumn{2}{c}{ Total Household Sample } & Households with Young Children \\
\hline City & $\boldsymbol{n}$ & $\mathbf{\%}$ & $\boldsymbol{n}$ & $\mathbf{\%}$ \\
\hline Blantyre & 432 & 6.7 & 241 & 9.6 \\
Cape Town & 1060 & 16.4 & 388 & 15.5 \\
Gaborone & 400 & 6.2 & 58 & 2.3 \\
Harare & 462 & 7.2 & 232 & 9.3 \\
Johannesburg & 996 & 15.4 & 277 & 11.1 \\
Lusaka & 400 & 6.2 & 221 & 8.8 \\
Manzini & 500 & 7.7 & 192 & 7.7 \\
Maputo & 397 & 6.2 & 226 & 9 \\
Maseru & 802 & 12.4 & 275 & 11 \\
Pietermaritzburg & 556 & 8.6 & 254 & 10.2 \\
Windhoek & 448 & 6.9 & 135 & 5.4 \\
Total & 6453 & 100 & 2499 & 100 \\
\hline
\end{tabular}

\subsection{Variable Descriptions}

This investigation measured household food consumption using the food item list in the Household Dietary Diversity Score (HDDS). The HDDS measures whether these food items were consumed by any member of the household in the last $24 \mathrm{~h}$ [57]. The food items included in the HDDS are: bread and other grains, potatoes and other foods made from roots or tubers, vegetables, fruits, red meats, eggs, fish or shellfish, beans or nuts, dairy, oils or other fats, sugars, and other foods such as condiments, coffee, or tea.

These food items were also used to measure the kinds of food items that household went without due to high food prices in the last six months. As a result, this food items list is used in this investigation to identify the foods that are commonly consumed and those food items that are vulnerable to in-access due to rising food prices. This investigation also measured the frequency with which households went 
without food due to rising food prices in the last six months. The investigation also measured the extent to which households had consistent or inconsistent access to water, medical care, and cooking fuel in the last year.

Finally, this study included the Household Food Insecurity Access Prevalence (HFIAP) that measured the frequency of household food access challenges in the month prior to the survey [58]. This scale is administered as a series of 9 sub-scale Likert questions measuring the frequency of social, physical, and economic experiences of limited food access by any member of the household. The score for this scale is derived using a weighted scoring algorithm that ranks household as: food secure, mildly food insecure, moderately food insecure, and severely food insecure. In addition, this investigation relied on the Months of Adequate Household Food Provisioning (MAHFP) scale to measure long-term household food access [59]. The scale measures the number of months in the last year during which a given household had access to adequate household food provisioning.

\subsection{Analysis}

In order to assess the change in the odds of household food security based on whether a household contains children aged 5 years and younger, this investigation will make use of odds ratios, Pearson's chi-square tests, and Fisher's exact tests. Odds ratios measure the change in odds of a household being categorized as food secure/insecure based on other characteristics (e.g., whether the household contains children aged 5 years old or younger). This investigation makes use of Pearson's chi-square tests and Fisher's exact tests to determine whether the distribution of households across any two variables is significantly non-random.

This investigation then provides descriptive statistics to indicate the experiences of food insecurity among poor urban households in the Southern African region that contain children aged 5 years old and younger. This analysis will highlight the potential impediments to attaining sufficient nutrition for these children and hypothesize the long-term ramifications of this experience for those children.

\section{Results}

\subsection{Research Objective One}

Across the board, households with children aged 5 years old and younger had greater representation among food insecure households when compared to households that did not contain children aged 5 years old and younger. That said, for each measure of food insecurity, most of the sampled poor urban households were categorized as food insecure on each measure (indicating the widespread prevalence of food insecurity among the sampled households) (Table 2). These findings demonstrate the widespread nature of food insecurity faced by the sampled poor households in cities across Southern Africa. These frequency distributions also indicate that the majority of the sampled households did not contain children aged 5 years old and younger.

Table 2. Descriptive statistics of household food security by households with children.

\begin{tabular}{cccccccc}
\hline Variable & Value & \multicolumn{2}{c}{ No Children } & \multicolumn{2}{c}{ Children $<\mathbf{5}$ Years } & \multicolumn{2}{c}{ Total } \\
\hline \multirow{2}{*}{ Food Price Impact } & & $\boldsymbol{n}$ & $\boldsymbol{\%}$ & $\boldsymbol{n}$ & $\mathbf{\%}$ & $\boldsymbol{n}$ & $\boldsymbol{\%}$ \\
& No & 825 & $67.8 \%$ & 392 & $32.2 \%$ & 1217 & $100 \%$ \\
& Yes & 2845 & $58.7 \%$ & 1998 & $41.3 \%$ & 4843 & $100 \%$ \\
\hline \multirow{2}{*}{ HFIAP * } & Food Secure & 707 & $70.6 \%$ & 295 & $29.4 \%$ & 1002 & $100 \%$ \\
& Food Insecure & 3081 & $58.8 \%$ & 2158 & $41.2 \%$ & 5239 & $100 \%$ \\
\hline \multirow{2}{*}{ MAHFP ** } & 12 Months & 1368 & $66.9 \%$ & 677 & $33.1 \%$ & 2045 & $100 \%$ \\
& $<12$ Months & 2423 & $58.1 \%$ & 1749 & $41.9 \%$ & 4172 & $100 \%$ \\
\hline
\end{tabular}

${ }^{*}$ Household Food Insecurity Access Prevalence. ${ }^{* *}$ Months of Adequate Household Food Provisioning. 
The odds ratio calculations of household food insecurity and the age of children contained in households validate many of the observations made via descriptive statistics. First, all of the food insecurity variables indicated a statistically significant relationship with households categorized based on the age of the children in the household. Second, households with children aged 5 years old and younger had greater odds of experiencing food insecurity according to each of the food insecurity measures included in this investigation when compared to households without children aged 5 years and younger (Table 3). While no other demographics were controlled in these findings, the results indicate a broad positioning of the sampled households with children in vulnerable conditions. Despite these findings, the odds ratios do not indicate a large increase in the odds of food insecurity based on the child membership in the sampled households. As a result, these findings are better interpreted as descriptive rather than predictive.

Table 3. Odds ratio calculations of household food security by households with children.

\begin{tabular}{|c|c|c|c|c|c|c|}
\hline \multirow[b]{2}{*}{ Variable } & \multicolumn{4}{|c|}{ 95\% C.I. } & \multirow[b]{2}{*}{$p$-Value } & \multirow[b]{2}{*}{$N$} \\
\hline & O.R. & Lower & Upper & $X^{2}$ & & \\
\hline $\begin{array}{l}\text { Food Price } \\
\text { Impact }\end{array}$ & 1.478 & 1.294 & 1.689 & 33.315 & $<0.001$ & 6060 \\
\hline HFIAP ** & 1.679 & 1.450 & 1.944 & 48.678 & $<0.001$ & 6241 \\
\hline MAHFP ** & 1.459 & 1.306 & 1.629 & 44.837 & $<0.001$ & 6217 \\
\hline
\end{tabular}

\subsection{Research Objective Two}

The sampled households with children 5 years old and younger demonstrated limited dietary diversity. The household survey data indicated that these households consumed just over 5 food groups, on average, in the last $24 \mathrm{~h}$. Among the foods consumed in the previous $24 \mathrm{~h}$, the most commonly consumed food types were bread, condiments, sugar, vegetables and oils (Table 4 ). $70 \%$ of the surveyed households with young children did not consume dairy in the previous $24 \mathrm{~h}$. Meats and beans were only consumed by a minority of these households. The surveyed households with young children also favored refined sugars over fruit consumption.

Table 4. Food Items Consumed by Households with Children 5 Years Old and Younger. HDDS: Household Dietary Diversity Score.

\begin{tabular}{lcc}
\hline HDDS Food Items Consumed in the Last $\mathbf{2 4} \mathbf{h}$ & $\boldsymbol{n}$ & $\mathbf{\%}$ \\
\hline Bread, rice noodles or any other locally available grain & 2408 & $96.9 \%$ \\
Other foods, such as condiments, coffee, tea & 1745 & $70.5 \%$ \\
Sugar or honey & 1741 & $70.1 \%$ \\
Vegetables & 1711 & $69.0 \%$ \\
Foods made with oil, fat, or butter & 1404 & $56.7 \%$ \\
Beef, pork, lamb, goat, rabbit, or other meat/organ meats & 990 & $39.8 \%$ \\
Potatoes, yams, manioc, cassava or other foods made from roots or tubers & 846 & $34.3 \%$ \\
Fruits & 740 & $30.0 \%$ \\
Cheese, yoghurt, milk or other milk products & 673 & $27.2 \%$ \\
Foods made from beans, peas, lentils, or nuts & 571 & $23.1 \%$ \\
Fresh or dried fish or shellfish & 495 & $20.0 \%$ \\
Eggs & 465 & $18.8 \%$ \\
\hline
\end{tabular}

The sampled households also demonstrated a high degree of food insecurity. Only $12 \%$ of the sampled households were categorized as food secure on the HFIAP (Household Food Insecurity Access Prevalence), while almost $60 \%$ were categorized as severely food insecure. These statistics indicate that food access challenges were a common experience among the sampled households. These findings were confirmed by the frequency with which the households went without food due to food 
prices in the last 6 months. Only $16 \%$ of the sampled households did not go without food due to rising food price in the last 6 months (Table 5). Finally, over $70 \%$ of the sampled households with young children experienced at least one month of insufficient food provisioning the previous year and $8 \%$ indicated that they did not have a single month of adequate food provisioning the previous year.

Table 5. Food Security and Food Price Impacts Among Households with Children 5 Years Old and Under.

\begin{tabular}{lcc}
\hline HFIAP & $n$ & $\%$ \\
\hline Food secure & 295 & $12.0 \%$ \\
Mildly food insecure access & 166 & $6.8 \%$ \\
Moderately food insecure access & 550 & $22.4 \%$ \\
Severely food insecure access & 1442 & $58.8 \%$ \\
\hline Food Price Impact & $n$ & $\%$ \\
\hline Never & 392 & $16.4 \%$ \\
About once a month & 573 & $24.0 \%$ \\
About once a week & 398 & $16.7 \%$ \\
More than once a week but less than everyday of the week & 649 & $27.2 \%$ \\
Every day & 378 & $15.8 \%$ \\
\hline Months of Adequate Household Food Provisioning & $n$ & $\%$ \\
\hline Zero Months in the Last Year & 197 & $8.1 \%$ \\
One Month in the Last Year & 16 & $0.7 \%$ \\
Two Months in the Last Year & 49 & $2.0 \%$ \\
Three Months in the Last Year & 26 & $1.1 \%$ \\
Four Months in the Last Year & 46 & $1.9 \%$ \\
Five Months in the Last Year & 57 & $2.3 \%$ \\
Six Months in the Last Year & 74 & $3.1 \%$ \\
Seven Months in the Last Year & 95 & $3.9 \%$ \\
Eight Months in the Last Year & 164 & $6.8 \%$ \\
Nine Months in the Last Year & 281 & $11.6 \%$ \\
Ten Months in the Last Year & 390 & $16.1 \%$ \\
Eleven Months in the Last Year & 354 & $14.6 \%$ \\
Twelve Months in the Last Year & 677 & $27.9 \%$ \\
\hline & & \\
\hline
\end{tabular}

Some key nutritional food items were not accessed by households in the last 6 months due to food prices. The sampled households with young children identified meats, dairy, eggs, fish, and fruits as largely inaccessible in the previous 6 months due to rising food prices (Table 6). This table may provide an explanation for some of the dietary trends observed among these sampled households so far in this investigation. Sugars and condiments were identified by these households as more affordable than meats or fruits. That said, it is likely that other factors like preference or availability may be at play. While vegetables were ranked by these households as the most affordable, this food item was not the most commonly consumed by these households in the previous $24 \mathrm{~h}$.

Those sampled households with children 5 years old and younger also demonstrated challenged access to key infrastructure resources. As an example, approximately $40 \%$ of the sampled households indicated inconsistent access to water and medical care in the last year. Of importance to household food security, about $60 \%$ of the sampled households also went without consistent access to cooking fuel in the last year. Limited access to cooking fuel limits the potential food items that a household can consume (Table 7). The limited access to these infrastructure services indicate the marginal coping capacity of these households to manage the onset of diseases. As a result, these findings demonstrate the limited adaptive capacity of these households in the face of long-wave nutrition-related health impacts. 
Table 6. Unaffordable food types for households with children aged 5 years and younger.

\begin{tabular}{lcc}
\hline Unaffordable Food Types & $\boldsymbol{n}$ & $\mathbf{\%}$ \\
\hline Beef, pork, lamb, goat, rabbit, or other meat/organ meats & 1310 & $66.9 \%$ \\
Cheese, yoghurt, milk or other milk products & 1237 & $63.2 \%$ \\
Bread, rice noodles or any other locally available grain & 1214 & $62.0 \%$ \\
Foods made with oil, fat, or butter & 1142 & $58.6 \%$ \\
Eggs & 1112 & $57.5 \%$ \\
Fresh or dried fish or shellfish & 1078 & $55.5 \%$ \\
Fruits & 1037 & $53.6 \%$ \\
Sugar or honey & 1000 & $51.8 \%$ \\
Potatoes, yams, manioc, cassava or other foods made from roots or tubers & 982 & $50.7 \%$ \\
Other foods, such as condiments, coffee, tea & 963 & $50.4 \%$ \\
Foods made from beans, peas, lentils, or nuts & 938 & $48.5 \%$ \\
Vegetables & 764 & $39.3 \%$ \\
\hline
\end{tabular}

Table 7. Poverty characteristics of households with children aged 5 years and younger.

\begin{tabular}{cccc}
\hline Resource Access & Access Consistency & $n$ & $\%$ \\
\hline Clean Water & Consistent Access & 1500 & $60.6 \%$ \\
& Inconsistent/No Access & 977 & $39.4 \%$ \\
Medical Care & Consistent Access & 1390 & $57.7 \%$ \\
& Inconsistent/No Access & 1021 & $42.3 \%$ \\
Cooking Fuel & Consistent Access & 975 & $40.2 \%$ \\
& Inconsistent/No Access & 1449 & $59.8 \%$ \\
\hline
\end{tabular}

\section{Discussion}

The findings from this investigation indicate that, among the sampled urban households in Southern Africa, households with children aged 5 years old and younger had increased odds of experiencing food insecurity when compared to households that did not contain children in this age bracket. When those households with children aged 5 years old and younger are assessed further, they demonstrated limited dietary diversity, widespread food insecurity, and vulnerability to food price increases with limited access to key urban infrastructure services. As a result, this investigation found that the children living in these households are susceptible to the long-term health implications of limited dietary diversity and inconsistent food access. In addition, the findings from this study identified the limited capacity of these households to manage the nutrition-related health outcomes of their current consumption.

These findings describe the vulnerability context of poor households with young children living in an access-based food swamp $[60,61]$. While further research will be needed to identify the long-wave health-outcomes of the nutritional patterns observed here, this investigation identified that the current dietary diversity of children growing up in poor urban households across Southern Africa suggests that they are positioned for sub-optimal physical and cognitive development (in addition to long-term nutrient-related diseases) [62-64]. Future longitudinal research should also investigate how the vulnerability context observed here might relate to the onset of communicable diseases as well.

These findings highlight the precarious position of many poor households with young children in Southern African cities and indicate a looming public health threat [60,61]. As Popkin et al. [38] noted, the widespread intake of sugars and saturated fats during infancy has the potential to instigate the onset of non-communicable diseases later in life and speed the epidemiological challenges predicted by both the nutrition transition and the epidemiological transition. Furthermore, the limited capacity of these households to maintain food security increases their vulnerability to communicable diseases like HIV, TB and the new disease-scape of antimicrobial resistant pathogens [26,56]. Given the urban transition underway in Africa over the coming decades [8,9], these vulnerabilities are likely to become exacerbated by poorly planned and implemented urbanization $[10,15]$. 


\section{Conclusions}

This study is not alone in suggesting that children are not all receiving sufficient food to develop fully, from conception through to adulthood [60,61]. The issue is not simply one of food availability [16,62], characterized in this paper as urban food swamps; nor is it only the distribution of that food, characterized more broadly in the literature as urban food deserts [51]. At the heart of the urban nutrition discussion is a more complex interplay of economic, social, political, infrastructural and environmental factors that together underpin the vulnerability of children (and adults) to hunger and malnutrition [21].

To end hunger (SDG 2) and to ensure health and well-being for all people (SDG 3), the international development agenda has to focus on food and nutrition security in urban areas, where the majority of people already live-or in the case of Africa-will live within the coming decade. Yet, with high levels of food and nutrition poverty in cities of the Global South (and Sub-Saharan Africa in particular), and with the long-term, negative impacts of poor-quality diets and resultant malnutrition on children, the very basis of much needed human capital to achieve sustainable development is undermined. On this specific point, Ogundaria and Awokuseb [63] argue that health is an even more important determinant than education in human capital development in Sub-Saharan Africa and is a crucial component of economic growth.

The urgency of childhood malnutrition cannot be overstated within the broader sustainable development debate [64] and further research that considers the prevalence of urban malnutrition in the context of adequate aggregate food supply is important within the broader food and nutrition security policy arena. Finally, as argued in this paper, while access to food affects nutrition outcomes (as in the case of food deserts), the ubiquitous presence of cheap, industrially manufactured food products (referred to as food swamps in this paper) has serious negative health implications for all people, but especially for children. Both research and policy must focus on food quality and not just availability and access to food.

Author Contributions: Conceptualization, B.F.; Methodology, B.F.; Validation, C.M.; Formal Analysis, B.F. and C.M.; Investigation, B.F.; Data Curation, B.F. and C.M.; Writing-Original Draft Preparation, B.F. and C.M.; Writing-Review \& Editing, B.F. and C.M.; Supervision, B.F.; Project Administration, B.F. and C.M.; Funding Acquisition, B.F.

Funding: This research was funded by the Canadian International Development Agency (CIDA Agreement No. S63441).

Acknowledgments: The research used in this paper was funded by the Canadian Government through the Canadian International Development Agency (CIDA) under its University Partners in Cooperation and Development (UPCD) Tier One Program. We wish to thank our colleagues in AFSUN for their assistance and wish to wish to thank the following for their assistance with research planning and implementation: Ben Acquah, Jane Battersby, Eugenio Bras, Asiyati Chiweza, David Coetzee, Bronwen Dachs, David Dorey, Scott Drimie, Miriam Grant, Gareth Haysom, Trevor Hill, Krista House, Florian Kroll, Clement Leduka, George Matovu, Chileshe Mulenga, Peter Mvula, Ndeyapo Nickanor, Sue Parnell, Wade Pendleton, Akiser Pomuti, Ines Raimundo, Michael Rudolph, Maria Salamone, Christa Schier, Nomcebo Simelane, Godfrey Tawodzera, Percy Toriro, Maxton Tsoka, Daniel Warshawsky and Lazarus Zanamwe.

Conflicts of Interest: The authors declare no conflict of interest.

\section{References}

1. Glaeser, E. Triumph of the City: How Our Greatest Invention Makes Us Richer, Smarter, Greener, Healthier, and Happier; Penguin: New York, NY, USA, 2012.

2. Tacoli, C.; Bukhari, B.; Fisher, S. Urban Poverty, Food Security and Climate Change; Human Settlements Working Paper 37; IIED: London, UK, 2013.

3. Frayne, B.; McCordic, C. Planning for food secure cities: Measuring the influence of infrastructure and income on household food security in Southern African cities. Geoforum 2015, 65, 1-11. [CrossRef]

4. United Nations. World Urbanization Prospects, The 2014 Revision; United Nations: New York, NY, USA, 2014.

5. Neuwirth, R. Shadow Cities: A Billion Squatters, A New Urban World; Routledge: New York, NY, USA, 2016.

6. Parnell, S.; Oldfield, S. The Routledge Handbook on Cities of the Global South; Routledge: London, UK, 2014. 
7. Parnell, S.; Pieterse, E. (Eds.) Africa's Urban Revolution; Zed Books: New York, NY, USA, 2014.

8. Montgomery, M.R. The urban transformation of the developing world. Science 2008, 319, 761-764. [CrossRef] [PubMed]

9. Montgomery, M.R. The demography of the urban transition: What we know and don't know. In The New Global Frontier; Martine, G., McGranahan, G., Montgomery, M., Fernandez-Castilla, R., Eds.; Routledge: London, UK, 2012; pp. 31-50.

10. Watson, V. Seeing from the south: Refocusing urban planning on the globe's central urban issues. Urban Stud. 2016, 46, 2259-2275. [CrossRef]

11. Mabin, A. Limits of urban transition models in understanding South African urbanisation. Dev. South. Afr. 1990, 7, 311-322. [CrossRef]

12. Kessides, C. The Urban Transition in Sub-Saharan Africa: Implications for Economic Growth and Poverty Reduction; Africa Region Working Paper No. 97; Cities Alliance: Washington, DC, USA, 2006.

13. Fox, S. Understanding the Origins and Pace of Africa's Urban Transition; Crisis States Research Centre Working Paper Series 2 No. 98; Crisis States Research Centre: London, UK, 2011.

14. Food and Agriculture Organization (FAO); International Fund for Agricultural Development (IFAD); United Nations International Children's Emergency Fund (UNICEF); World Food Programme (WFP); World Health Organization (WHO). The State of Food Security and Nutrition in the World 2018: Building Climate Resilience for Food Security and Nutrition; FAO: Rome, Italy, 2018.

15. Dunkelman, A.; Kerr, M.; Swatuk, L.A. The New Green Revolution: Enhancing Rainfed Agriculture for Food and Nutrition Security in Eastern Africa. In Water, Energy, Food and People Across the Global South; Swatuk, L., Cash, C., Eds.; Palgrave Macmillan: New York, NY, USA, 2018; pp. 305-324.

16. Frayne, B.; Crush, J.; McCordic, C. (Eds.) Food and Nutrition Security in Southern African Cities; Routledge: London, UK, 2017.

17. Ruel, M.T.; Garrett, J.; Yosef, S.; Olivier, M. Urbanization, food security and nutrition. In Nutrition and Health in a Developing World; de Pee, S., Taren, D., Bloem, M., Eds.; Humana Press: New York, NY, USA, 2017; pp. 705-735.

18. Holding, P.A.; Fotso, J.C. Psychological developments and their correlates in sub-Saharan Africa. In Child and Adolescent Development: An Expanded Focus on Public Health in Africa; Tomlinson, M., Hanlon, C., Stevenson, A., Eds.; University of Cape Town Press: Claremont, South Africa, 2018; pp. 207-245.

19. Bundy, D.A.; De Silva, N.; Horton, S.; Jamison, D.T. (Eds.) Disease Control Priorities, (Volume 8): Child and Adolescent Health and Development; World Bank Publications: Washington, DC, USA, 2017.

20. Bhutta, Z.A.; Das, J.K.; Rizvi, A.; Gaffey, M.F.; Walker, N.; Horton, S.; Webb, P.; Lartey, A.; Black, R.E.; Lancet Nutrition Interventions Review Group, the Maternal and Child Nutrition Study Group. Evidence-based interventions for improvement of maternal and child nutrition: What can be done and at what cost? Lancet 2013, 382, 452-477. [CrossRef]

21. Horton, R.; Lo, S.; Lemma, F.; Matji, J.; Pinstrup-Andersen, P.; Nabarro, D. Nutrition: A quintessential sustainable development goal. Lancet 2013, 382, 452-477. [CrossRef]

22. United Nations Development Programme (UNDP). What Does It Mean to Leave No One Behind? A UNDP Discussion Paper and Framework for Implementation; UNDP: New York, NY, USA, 2018.

23. World Food Programme (WFP); Food and Agriculture Organization (FAO). The State of Food Insecurity in the World: Addressing Food Insecurity in Protected Crises; WFP; FAO: Rome, Italy, 2010.

24. UNDP. Africa Human Development Report 2012: Towards a Food Secure Future; United Nations Development Programme Regional Bureau for Africa: New York, NY, USA, 2012.

25. Wilkinson, R.G. The epidemiological transition: From material scarcity to social disadvantage? Daedalus 1994, 123, 61-77. Available online: https:/ /www.jstor.org/stable/20027267 (accessed on 1 November 2018). [PubMed]

26. Harper, K.; Armelagos, G. The changing disease-scape in the third epidemiological transition. Int. J. Environ. Res. Public Health 2010, 7, 675-697. [CrossRef] [PubMed]

27. Omran, A.R. The epidemiologic transition: A theory of the epidemiology of population change. Milbank $Q$. 2005, 83, 731-757. [CrossRef] [PubMed]

28. Wilkinson, R.G. Socioeconomic determinants of health: Health inequalities: Relative or absolute material standards? BMJ 1997, 314, 591. [CrossRef] [PubMed] 
29. Santosa, A.; Wall, S.; Fottrell, E.; Högberg, U.; Byass, P. The development and experience of epidemiological transition theory over four decades: A systematic review. Glob. Health Action 2014, 7, 23574. [CrossRef] [PubMed]

30. Dye, C.; Trunz, B.B.; Lönnroth, K.; Roglic, G.; Williams, B.G. Nutrition, diabetes and tuberculosis in the epidemiological transition. PLoS ONE 2011, 6, e21161. [CrossRef] [PubMed]

31. Uauy, R.; Kain, J. The epidemiological transition: Need to incorporate obesity prevention into nutrition programmes. Public Health Nutr. 2002, 5, 223-229. [CrossRef] [PubMed]

32. Broyles, S.T.; Denstel, K.D.; Church, T.S.; Chaput, J.P.; Fogelholm, M.; Hu, G.; Kuriyan, R.; Kurpad, A.; Lambert, E.V.; Maher, C.; et al. The epidemiological transition and the global childhood obesity epidemic. Int. J. Obes. Suppl. 2015, 5 (Suppl. 2), S3-S8. [CrossRef]

33. Drewnowski, A.; Popkin, B.M. The nutrition transition: New trends in the global diet. Nutr. Rev. 1997, 55, 31-43. [CrossRef] [PubMed]

34. Shetty, P. Nutrition transition and its health outcomes. Indian J. Pediatr. 2013, 80, 21-27. [CrossRef] [PubMed]

35. Popkin, B.M. The shift in stages of the nutrition transition in the developing world differs from past experiences! Public Health Nutr. 2002, 5, 205-214. [CrossRef] [PubMed]

36. Popkin, B.M. The nutrition transition in the developing world. Dev. Policy Rev. 2003, 21, 581-597. [CrossRef]

37. Doak, C.M.; Adair, L.S.; Bentley, M.; Monteiro, C.; Popkin, B.M. The dual burden household and the nutrition transition paradox. Int. J. Obes. 2005, 29, 129-136. [CrossRef] [PubMed]

38. Popkin, B.M.; Adair, L.S.; Ng, S.W. Global nutrition transition and the pandemic of obesity in developing countries. Nutr. Rev. 2012, 70, 3-21. [CrossRef] [PubMed]

39. Popkin, B.M. The nutrition transition and obesity in the developing world. J. Nutr. 2001, 131, 871-873. [CrossRef] [PubMed]

40. Popkin, B.M.; Gordon-Larsen, P. The nutrition transition: Worldwide obesity dynamics and their determinants. Int. J. Obes. 2004, 28 (Suppl. 3), S2-S9. [CrossRef]

41. Kimani-Murage, E.W.; Muthuri, S.K.; Oti, S.O.; Mutua, M.K.; van de Vijver, S.; Kyobutungi, C. Evidence of a double burden of malnutrition in urban poor settings in Nairobi, Kenya. PLoS ONE 2015, 10, e0129943. [CrossRef] [PubMed]

42. Keino, S.; Plasqui, G.; Ettyang, G.; van den Borne, B. Determinants of stunting and overweight among young children and adolescents in sub-Saharan Africa. Food Nutr. Bull. 2014, 35, 167-178. [CrossRef] [PubMed]

43. Steyn, N.P.; Labadarios, D.; Nel, J.; Kruger, H.S.; Maunder, E.M. What is the nutritional status of children of obese mothers in South Africa? Nutrition 2011, 27, 904-911. [CrossRef] [PubMed]

44. Drimie, S.; Faber, M.; Vearey, J.; Nunez, L. Dietary diversity of formal and informal residents in Johannesburg, South Africa. BMC Public Health 2013, 13, 911. [CrossRef] [PubMed]

45. Frayne, B.; Crush, J.; McLachlan, M. Urbanization, nutrition and development in Southern African cities. Food Secur. 2014, 6, 101-112. [CrossRef]

46. Battersby, J.; Peyton, S. The geography of supermarkets in Cape Town: Supermarket expansion and food access. Urban Forum 2014, 25, 153-164. [CrossRef]

47. D'Rozario, D.; Williams, J.D. Retail redlining: Definition, theory, typology, and measurement. J. Macromark. 2005, 25, 175-186. [CrossRef]

48. Peyton, S.; Moseley, W.; Battersby, J. Implications of supermarket expansion on urban food security in Cape Town, South Africa. Afr. Geogr. Rev. 2015, 34, 36-54. [CrossRef]

49. Battersby, J.; Crush, J. Africa's urban food deserts. Urban Forum 2014, 25, 143-151. [CrossRef]

50. Shaw, H.J. Food deserts: Towards the development of a classification. Geogr. Ann. Ser. B Hum. Geogr. 2006, 88, 231-247. [CrossRef]

51. Crush, J.; Battersby, J. (Eds.) Rapid Urbanisation, Urban Food Deserts and Food Security in Africa; Springer: London, UK, 2016.

52. Battersby, J. Urban food insecurity in Cape Town, South Africa: An alternative approach to food access. Dev. S. Afr. 2011, 28, 545-561. [CrossRef]

53. Cooksey-Stowers, K.; Schwartz, M.B.; Brownell, K.D. Food swamps predict obesity rates better than food deserts in the United States. Int. J. Environ. Res. Public Health 2017, 14, 1366. [CrossRef] [PubMed]

54. Bridle-Fitzpatrick, S. Food deserts or food swamps? A mixed-methods study of local food environments in a Mexican city. Soc. Sci. Med. 2015, 142, 202-213. [CrossRef] [PubMed] 
55. Caesar, M.Z.; Crush, J.N. The triple burden of HIV, TB and food insecurity. In Food and Nutrition Security in Southern African Cities; Frayne, B., Crush, J., McCordic, C., Eds.; Routledge: London, UK, 2017; pp. $135-155$.

56. Crush, J.; Drimie, S.; Frayne, B.; Caesar, M. The HIV and urban food security nexus in Africa. Food Secur. 2011, 3, 347-362. [CrossRef]

57. Swindale, A.; Bilinsky, P. Household Dietary Diversity Score (HDDS) for Measurement of Household Food Access: Indicator Guide; USAID: Washington, DC, USA, 2005.

58. Coates, J.; Swindle, A.; Bilinsky, P. Household Food Insecurity Access Scale (HFIAS) for Measurement of Food Access: Indicator Guide; Version 3; USAID: Washington, DC, USA, 2007.

59. Bilinsky, P.; Swindale, A. Months of Adequate Household Food Provisioning (MAHFP) for Measurement of Household Food Access: Indicator Guide; Version 4; USAID: Washington, DC, USA, 2010.

60. Hirvonen, K.; Hoddinott, J.; Minten, B.; Stifel, D. Children's diets, nutrition knowledge, and access to markets. World Dev. 2017, 95, 303-315. [CrossRef]

61. Arimond, M.; Ruel, M.T. Dietary diversity is associated with child nutritional status: Evidence from 11 demographic and health surveys. J. Nutr. 2004, 134, 2579-2585. [CrossRef] [PubMed]

62. Crush, J.; Frayne, B.; Pendleton, W. The crisis of food insecurity in African cities. J. Hunger Environ. Nutr. 2012, 7, 271-292. [CrossRef]

63. Ogundari, K.; Awokuse, T. Human capital contribution to economic growth in Sub-Saharan Africa: Does health status matter more than education? Econ. Anal. Policy 2018, 58, 131-140. [CrossRef]

64. United Nations International Children's Emergency Fund (UNICEF); World Health Organization (WHO); World Bank Group. Levels and Trends in Child Malnutrition: Joint Child Malnutrition Estimates: Key Findings of the 2017 Edition; UNICEF: New York, NY, USA, 2017.

(C) 2018 by the authors. Licensee MDPI, Basel, Switzerland. This article is an open access article distributed under the terms and conditions of the Creative Commons Attribution (CC BY) license (http:/ / creativecommons.org/licenses/by/4.0/). 